\title{
Movimientos socioambientales, decolonialidad e historia ambiental en los conflictos patagónicos en Argentina (1980-2003)
}

\section{Socio-environmental movements, decoloniality and environmental history in the Patagonian conflicts in Argentina (1980-2003)}

Ayelen Dichdji*

Resumen: La presente investigación propone analizar el surgimiento de controversias alrededor de la emergencia de los primeros conflictos socioambientales, que captaron la atención de la opinión pública en Argentina entre 1980 y 2003, tomando en consideración dos casos emblemáticos: Gastre y Esquel, ambos situados en la Patagonia argentina. Nos proponemos establecer un recorrido histórico-ambiental donde tenga preminencia una matriz teóricometodológica integral constituida por: historia ambiental, estudios decoloniales y comunicación de riesgo. Como fuentes de análisis emplearemos diarios de tirada nacional como Clarín y La Nación.

Palabras claves: Chubut; movimientos sociales; recursos naturales; controversias; decolonialidad

\begin{abstract}
The present investigation proposes to analyze the emergence of controversies around the emergence of the first socio-environmental conflicts, which caught the attention of public opinion in Argentina between 1980 and 2003, taking into account two emblematic cases: Gastre and Esquel, both located in Patagonia Argentina. We intend to establish a historical-environmental journey with a comprehensive theoretical-methodological matrix consisting of: environmental history, decolonial studies and risk communication. As sources of analysis we will use national newspapers such as Clarín and La Nación.
\end{abstract}

Keywords: Chubut; social movements; natural resources; controversies; decoloniality

\footnotetext{
* Doctora en Ciencias Sociales y Humanas (UNQ), y licenciada en Comunicación Social (UNQ). Doctoranda en Historia y Arte por la Universidad de Granada (España). Becaria postdoctoral (CONICET) y miembro del Centro de Estudios de la Argentina Rural (CEAR). Actualmente se desempeña como docente del curso de posgrado "Ambiente, desarrollo y cultura en la ruralidad" (UNQ). Es miembro del Consejo Asesor del CEAR y editora de la revista Estudios Rurales en la sección "Debates contemporáneos".
} 


\section{Introducción}

La relación sociedad humana-ambiente natural se torna compleja de abordar puesto que, como sostiene García (2011), una civilización que cree que la naturaleza le pertenece para dominarla y que dispone de una tecnología poderosa "tiene la misma probabilidad de sobrevivir que una bola de nieve a mitad del infierno" (p.293). El quid de la cuestión, que está de fondo en los análisis de esta índole, es la crítica a la razón instrumental que se impone bajo la premisa de: "conocer para dominar, regular y controlar la naturaleza sin prever las consecuencias para la vida de esta masiva e irreflexiva intervención en el mundo natural" (LEZAMA, 2004, p. 327). Algo que, para la Escuela de Frankfurt, por ejemplo, se entiende como la dominación del ser humano sobre el mundo exterior; así, “dominar la naturaleza se tradujo en destruirla y con ello en autodestrucción de la vida humana” (ADORNO y HORKHEIMER, 1979, p.327). En consecuencia, lo antedicho coloca en la encrucijada el paradigma del progreso como inocuo, positivo, sin riesgo, equilibrado y equitativo. Por consiguiente, se requiere un enfoque que complemente tanto las ciencias naturales como las sociales, permita un abordaje holístico de la problemática y proponga posibles lecturas para resolver estas cuestiones.

En este contexto, Rojas y Gallardo (2017) sostienen que la historia ambiental ha incrementado el "número de investigaciones, expresándose como un campo altamente interdisciplinario y con el desarrollo de abordajes y metodologías que en ocasiones han fomentado el diálogo entre las ciencias naturales y las sociales” (p.22). De esta manera, supera los parámetros metodológicos tradicionales del campo histórico, permitiendo la incorporación de los historiadores en la discusión por brindar un contexto histórico a los conflictos ambientales.

En este sentido, el objetivo de la presente investigación propone analizar el surgimiento de controversias alrededor de la emergencia de los primeros conflictos socioambientales que captaron la atención de la opinión pública (HABERMAS, 1973) ${ }^{1}$ en Argentina entre 1980 y 2003, tomando en consideración

\footnotetext{
${ }^{1}$ Para Habermas (1973) toda discusión pública se presenta como la única posibilidad de superar los conflictos sociales, en parte, gracias a la búsqueda de consensos que permitan el acuerdo y la cooperación a pesar de los disensos (BOLADERO CUCURELLA, 2001, p.53). En tal sentido,
} 
fundamentalmente dos casos emblemáticos: Gastre y Esquel, ambos situados en la Patagonia argentina. ¿Qué factores convocan la participación ciudadana en los conflictos ambientales? ¿Cómo se construye la resistencia frente a la amenaza socioambiental? ¿Cómo se desarrolla cada conflicto? ¿Quiénes fueron los actores sociales involucrados? ¿Cuáles fueron las acciones colectivas que se realizaron para afrontar la problemática en cada caso? ¿Qué tipo de discursos estuvieron presentes durante ambos conflictos? ¿Qué rol tuvo la prensa gráfica en la difusión de cada problema socioambiental? Sin pretensiones de exhaustividad estos serán algunos de los interrogantes que guiarán esta investigación.

Por consiguiente, nos proponemos establecer un recorrido históricoambiental donde tenga preminencia una matriz teórico-metodológica integral. Con tal fin, trabajaremos con las herramientas brindadas por la historia ambiental, los estudios decoloniales y la comunicación de riesgo. Como fuentes de análisis emplearemos diarios de tirada nacional como Clarín y La Nación, en tanto fuentes históricas de conocimiento sobre el pasado reciente. En este punto, los debates públicos que se plantean en los medios de comunicación en Argentina sobre los conflictos socioambientales suelen evitar, por lo menos, dos esferas: las raíces económicas del conflicto y los intereses políticos que se encuentran imbricados en cada problema ambiental. En este aspecto, es común encontrar coberturas mediáticas sobre celebraciones organizadas por movimientos ambientalistas, campañas de reciclaje, actividades propuestas por $\mathrm{ONG}^{\prime} \mathrm{s}$ "verdes"; pero cuando se trata de acontecimientos de riesgo el acento frecuentemente se encuentra en las inclemencias del tiempo, los desastres, amenazas y catástrofes "naturales”, entre otros términos comúnmente utilizados. Es decir que, existe una deformación en la manera de entender y presentar los conflictos ambientales. En principio, porque esas calificaciones suponen invertir la responsabilidad del hecho ocurrido a "fuerzas naturales" o "sobrenaturales" que atentan irremediablemente en contra del ser humano. Otra malinterpretación en atribuir la carga negativa sobre la naturaleza, considerando su "acción maléfica” por encima de otras causas, como las condiciones políticas y los intereses económicos que se esconden detrás de estos acontecimientos. En muchos casos estas representaciones son reforzadas y difundidas por los medios

considera la opinión pública como una pieza clave de su propuesta de política deliberativa, una alternativa para superar los déficits democráticos de las políticas contemporáneas. 
de comunicación. Política, economía, naturaleza, democracia, ciudadanía y comunicación lejos de ser esferas disociadas entre sí, están estrechamente vinculadas. Así, los medios de comunicación tienen una función primordial en la construcción de imágenes y discursos sobre los conflictos socioambientales.

Por otro lado, en esta investigación, trabajamos con la noción de movimientos sociales entendidos como aquellos actores sociales focalizados en realizar un cambio cultural y de valores por medio de actos de resistencia (CASTELLS, 2009). Puntualmente, dentro de esa categoría, nos interesan los movimientos ambientalistas que conciben la necesidad de luchar, individual y colectivamente, con objetivos concretos que permitan concientizar a la sociedad respecto al daño causado por el hombre en el mundo natural (LEFF, 1986). Como consecuencia, en Argentina, los movimientos ambientalistas surgen conforme a la perspectiva latinoamericana producto de la interconexión de factores ambientales, sociales, políticos y económicos. Por ello la problemática ambientalista en el país se encuentra asociada a los conflictos socioambientales. Como menciona Leff (1986), la cuestión ambiental es una problemática eminentemente social, generada por un conjunto de procesos económicos, políticos, jurídicos, sociales y culturales. Ejemplos claros de lo antedicho son los casos de estudio que desarrollaremos en estas páginas.

\section{Chubut, semillero de la batalla decolonial en conflictos socioambientales en Argentina}

La República Argentina está compuesta por 23 provincias, una de ellas es Chubut y se encuentra en la zona patagónica al sur del país. Situada en el centro de la región está dominada por los climas áridos en casi toda su extensión. Las particularidades del relieve determinan la existencia de tres ambientes geográficos bien diferenciados: la cordillera, la meseta y el litoral atlántico. Cada uno se caracteriza por un subtipo particular de clima y bioma. El monte característico del oriente provincial se convierte en una estepa de vegetación seca en el centro del territorio. Ambas formaciones típicas de climas áridos contrastan con la exuberancia del bosque húmedo que cubre las laderas andinas en el extremo occidental de la provincia.

A su vez, el territorio provincial comprende dos regiones diferentes: al este, la meseta patagónica y, al oeste, la cordillerana. La meseta presenta, por un lado, 
las extensas planicies, que se denominan pampas; por el otro, las sierras, cuyas alturas varían entre los 1.000 y los 1.800 metros de altura; como también los valles fluviales que la atraviesan en dirección oeste-este. Asimismo, cuenta con zonas deprimidas denominadas bajos que alcanza los 45 metros bajo el nivel del mar. La presencia de numerosos ríos que se alimentan del deshielo cordillerano, y diversos lagos y lagunas, es el rasgo característico de la hidrografía de esta porción del territorio patagónico. Mientras que, en la meseta el clima es frío y seco, con veranos cortos e inviernos prolongados; en la cordillera, el clima es frío y húmedo. La vegetación de la meseta es del tipo estepario, con pastos ralos y sin árboles; pero, en la cordillera predomina el bosque.

Además de sus paisajes naturales la zona se caracteriza por una economía compuesta por diversas actividades: agrícola, pesca industrial, petróleo, ganadería, forestación e industrias varias. Políticamente Chubut está dividida en 15 departamentos, entre ellos: el Departamento de Gastre, donde se ubica la localidad homónima; y el Departamento de Futaleufú, donde encontramos la localidad de Esquel. Asimismo, se extiende desde los Andes patagónico-fueguinos hasta el océano Atlántico. En este sentido, limita al norte con la provincia de Río Negro, al sur con la provincia de Santa Cruz, al oeste con la cordillera de los Andes y al este con el mar argentino. Cuenta con una superficie de $224.686 \mathrm{~km} 2$ y es la cuarta provincia argentina en extensión.

En 1991 la población era de 357.189 habitantes (440 pobladores en Gastre; 30.782 en Esquel), mientras que hacia el año 2000 era de 413.237 habitantes (557 en Gastre; 28.089 en Esquel), según establecen los datos del Instituto Nacional de Estadística y Censos (INDEC, 1991; INDEC, 2001). En relación con el clima, cabe destacar que no es homogéneo, por el contrario, se pueden advertir tres clases según la zona: el sector de los Andes, la zona de las mesetas y terrazas y el área de Península de Valdés.

En lo que refiere a la economía del lugar, como mencionábamos al comienzo, Chubut es una de las provincias que cuenta con mayor cantidad de producción ovina de Argentina convirtiéndose en líder en la exportación lanera. Además, produce y exporta de carne ovina, bovina y pesca. Por otra parte, la zona cuenta con yacimientos de diversos metales: plomo, zinc, plata, oro, cobre, estaño y antimonio. Sin ir más lejos, durante la década de 1980 se inició en Esquel la 
exploración de oro considerando la zona como propicia para la actividad minera.

En sintonía, también se busca la explotación petrolera del lugar.

Mapa 1: Provincia de Chubut, Argentina

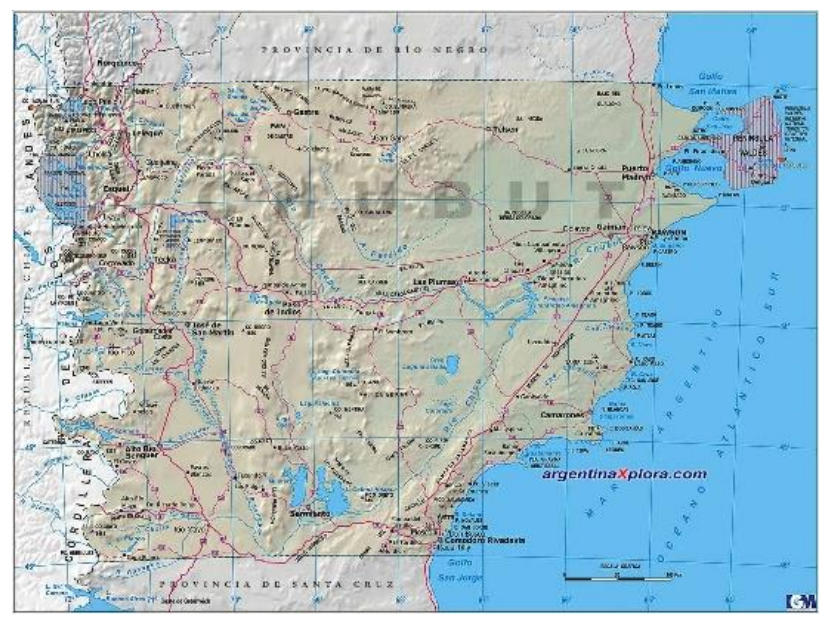

Fuente: Argentina Explora

En otro orden, a nivel internacional, en la década de 1980 se produce el mayor desastre nuclear conocido hasta ese momento en el mundo: estalla el reactor de Chérnobil en Ucrania, dejando contaminado al territorio occidental de la URSS y llegando a Europa Occidental. Todavía en la actualidad la zona es inhabitable. Este hecho propició el incremento de las protestas y demandas de los ciudadanos europeos para poner fin a los programas nucleares. Dos meses después de este trágico hecho, al otro lado del Atlántico, la Comisión Nacional de Energía Atómica (CNEA) ${ }^{2}$ de Argentina informa, sin previa consulta o discusión con los pobladores de la localidad de Gastre, que contaban con un proyecto para instalar un repositorio nuclear en la zona y que ya se encontraba habilitado. Dicho proyecto, se presenta a la población como una posibilidad de incrementar las fuentes de trabajo. Una falacia que escondía el verdadero objetivo: convertir a la Patagonia argentina en el basurero nuclear del mundo. La oposición a este programa no se hizo esperar y se consolidó como la primera controversia $^{6}$ y el primer testimonio de conflicto ambiental en el país 3 .

\footnotetext{
${ }^{2}$ La Comisión Nacional de Energía Atómica (CNEA) fue fundada en la década de 1950 mediante el Decreto del Poder Ejecutivo Nacional $\mathrm{N}^{0} 10936 / 50$.

3 Gastre es considerado un referente histórico, caso inicial y testigo de las luchas en conflictos socioambientales en Argentina. Se posiciona como un claro ejemplo de los resultados que se pueden obtener gracias a la movilización social, toma de consciencia, organización conjunta; como también la repercusión y magnitud que ha alcanzado tanto a nivel nacional como regional. Asimismo, fue el punto inaugural de un cúmulo de recorridos ciudadanos en rechazo a diversos proyectos que atentan contra la salud del ambiente y la sociedad en diferentes puntos geográficos
} 
Mapa 2 : Localidad de Gastre y Esquel, provincia de Chubut, Argentina

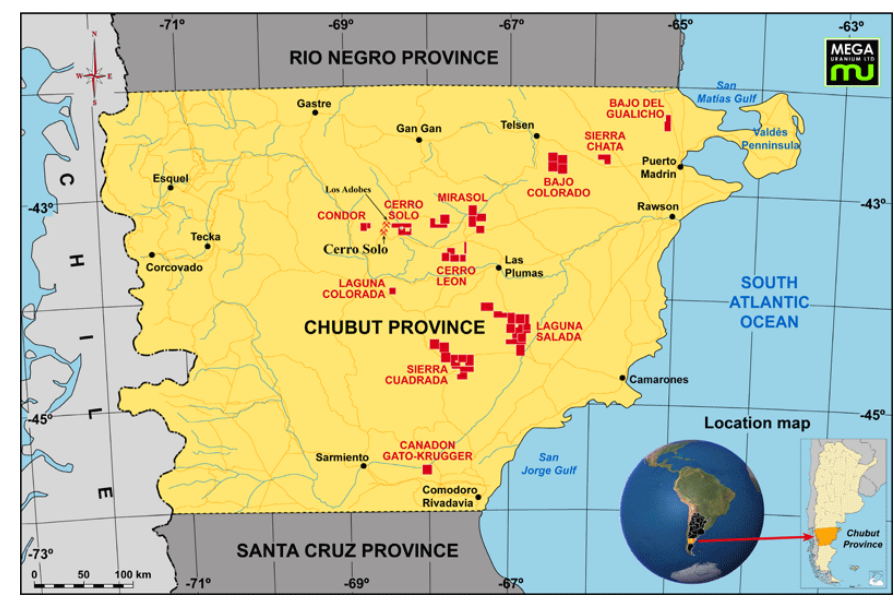

Fuente: La opinión Austral

A raíz de esta situación los vecinos de la zona afectada elaboraron el Manifiesto Antinuclear de Chubut, el cual establecía 40 puntos que daban cuenta de la postura adquirida por la población. En este documento se declaraba, entre otras cosas: la inexistencia de repositorios nucleares de esta magnitud en el mundo; la peligrosidad que conllevan los residuos radioactivos; además, se señala que Argentina no cuenta con la cantidad de desechos que amerite una construcción de esta envergadura, lo cual invita a sospechar de una doble intención para importar basura del exterior. También se manifiesta la generación de diversas enfermedades, entre ellas el cáncer, y deformaciones por el contacto con estas sustancias en el aire, suelo y agua. Se subraya, además, que en algunos países del primer mundo es obligación consultar por voto popular antes de instalar centrales nucleares; por otro lado, en la República Argentina para la época son cada vez más los municipios declarados no nucleares. Son varias las provincias que legislaron contra la instalación de repositorios y tránsito de residuos nucleares.

La Constitución de la provincia de Chubut -sancionada el 11 de octubre de 1994- es tajante: "quedan prohibidos en la provincia la introducción, el transporte y el depósito de residuos de origen extraprovincial, radioactivos, tóxicos, peligrosos o susceptibles de serlo". Por consiguiente, el basurero nuclear de Gastre sería incompatible con la eventual explotación minera del norte de la provincia de Chubut. Sumado a esto, la existencia ulterior del basurero es

de Argentina. La mayor parte de ellos vinculados a la minería a cielo abierto, a la deforestación, al uso de agrotóxicos, entre otros. 
incompatible con el desarrollo turístico de las provincias de Chubut, Rio Negro, Neuquén, y la Patagonia entera. Como también sería incompatible con la explotación ganadera y la exportación de su lana. Estos son, entre otros puntos, lo que se pueden encontrar en el Manifiesto (Rodríguez Pardo, 2007). De la mano de este documento, que dio luz verde a las acciones colectivas 4 en la zona en contra de este proyecto, emerge al Movimiento Antinuclear del Chubut (MACH) como primera organización constituida íntegramente por los vecinos de la provincia patagónica. Una de las ONG más longevas del sur de Argentina.

Los cuestionamientos sobre el impacto que el desarrollo e implementación del proyecto podía generar en el ambiente y en la salud eran numerosos, como veremos más adelante. Sin embargo, no se puede desconocer que no fue ni el único ni el último caso donde una población se enfrenta a procesos políticos, económicos que atentan contra los recursos naturales y las condiciones de vida presentes y futuras de los habitantes en el país.

Frente al creciente surgimiento de los conflictos socioambientales en Argentina, se destacan aquellos vinculados a los proyectos extractivos de minería a cielo abierto. Como sostiene Wagner (2016), el rechazo a estas iniciativas consolidó la emergencia de movimientos sociales y la legislación restrictiva en, por lo menos, siete provincias del país. En este sentido, la década de los noventa se presenta como el contexto primordial con la llegada de inversores extranjeros a la actividad y la modificación del Código de Minería que privilegia la inserción de empresas privadas incrementando la explotación minera en el país.

El caso de Esquel (Chubut) fue pionero en resistir desde el 2002 a la instalación del proyecto minero de extracción de oro en la localidad. Una vez más, la Patagonia se levanta para defender sus recursos y calidad de vida. Esquel se transformó en el ícono del "No a la Mina" en Argentina, como podremos advertir en este trabajo, colocando un manto de incertidumbre sobre los potenciales riesgos de los proyectos mineros metalíferos, especialmente sobre aquellos que utilizaban cianuro para separar el mineral de la roca (WAGNER, 2002). Los pobladores de Chubut conformaron, a raíz de este conflicto, un nuevo

4Scribano (2005) precisa que los movimientos sociales constituyen formas de acción colectiva que institucionalizan una acción entre metas, recursos e identidad. Sostenemos junto a Wagner (2014), entonces, que la acción colectiva supone hacer referencia a "un actor social colectivo que presenta menores garantías respecto a su continuidad, su nivel de integración interna, su estructura y organización, la construcción de una identidad y la planificación de tácticas y estrategias" (pp. 45-46). 
movimiento: la Asociación de Vecinos Autoconvocados de Esquel (AVAE), con una constitución heterogénea que nuclea -nuevamente y como aconteció en el caso de Gastre- a docentes, comerciantes, artistas, jóvenes, etc., para resistir. En la actualidad, la lucha continúa vigente en esta localidad reavivando las discusiones sobre la actividad minera y la protección de los recursos naturales.

\title{
Hacia una propuesta teórico-metodológica
}

La presente investigación se desarrolla elaborando un esquema teóricometodológico pluridisciplinar donde entran en juego herramientas provistas por la perspectiva histórico-ambiental, los estudios decoloniales y la comunicación de riesgos. Por consiguiente, estamos en presencia de un trabajo cualitativo, cuantitativo, descriptivo y exploratorio.

En tal sentido, el ambiente puede ser interpretado, y de hecho lo es, desde una pluralidad de puntos de vista que visibilizan experiencias y valores culturales entre las comunidades y las instituciones (NYGREN, 2012). Por consiguiente, los estudios sobre la interacción entre las sociedades humanas con la naturaleza necesariamente conectan características sobre el uso, acceso y control de las cuestiones ambientales en sintonía con los vínculos de poder, las representaciones sociales y culturales, etc. (PEET y WATTS, 2002). Así,

\begin{abstract}
las representaciones culturales juegan un papel importante en la formación de las percepciones ambientales y de las acciones políticas y también en la legitimación de ciertas políticas y percepciones ambientales, mientras que las políticas públicas juegan un papel destacado en la institucionalización de cierto tipo de conocimiento y manejo ambiental (Escobar, 2008). (En NYGREN, 2012, p. 12)
\end{abstract}

Por lo tanto, resulta esencial prestar especial atención la heterogeneidad presente en los conflictos socioambientales en todas las escalas. Para Coser (1970) un conflicto implica momentos de quiebre en los órdenes sociales existentes “dando lugar a la emergencia de una nueva estructura”. Así, el conflicto se traduce como una colisión entre valores e intereses, una tensión entre lo que algunos grupos consideran que debe ser y lo que efectivamente ocurre (p.2). Bobbio, Matteucci y Pasquino (1991), sostienen que hablar de conflicto obliga pensar en la forma de interacción entre los individuos, las organizaciones, los grupos y las colectividades en virtud del acceso a los recursos naturales, su distribución y los enfrentamientos que de esa interacción desprenden (p. 298). 
Buckles (2000) indica que son la síntesis entre una forma peculiar, y altamente contradictoria, en la cual cada territorio, en sintonía con sus recursos y las comunidades que lo habitan, se incorporan al modelo de desarrollo imperante y tejen vínculos de poder (PAZ, 2012).

Estas observaciones permiten posicionarnos en lo que Gudynas (2016) ha denominado para Latinoamérica como extractivismo5, entendido como "la apropiación de recursos naturales en grandes volúmenes o bajo prácticas de alta intensidad, para nutrir masivas exportaciones hacia la globalización” (p. 13). Cabe destacar como claro ejemplo de este modelo, aunque no exclusivo, la minería a cielo abierto. Una actividad que implica diversos impactos socioambientales, territoriales, económicos y culturales en las zonas donde se ejecuta; dando lugar al surgimiento de conflictos sociales donde comunidades locales -como podremos advertir a lo largo de este trabajo- se ven perjudicadas y comienzan actos de resistencia no violenta y denuncias concretas por verse vulnerados sus derechos a un ambiente sano. Como resalta Gudynas (2016) "es una problemática que cruza todo el abanico de ideologías político-partidarias, ya que asoman los extractivismos tanto en gobiernos conservadores como (...) socialistas" (p.16). De una u otra manera, es innegable el impacto negativo que acapara tanto para la salud humana como para el ambiente. En definitiva, como mencionan Braun y Wainwraight (2001) y Sismondo (1993) hay que entender cómo la naturaleza es socializada y la sociedad naturalizada (Guzmán y Madrigal, 2016).

Así, desde la perspectiva de los estudios decoloniales, como menciona Parra-Romero (2016)

$\mathrm{Al}$ reconocer la colonialidad como un dispositivo que cientifiza, objetualiza y mercantiliza la naturaleza y desplegar las herencias coloniales que, después del colonialismo, ejercen formas de dominar la naturaleza y los cuerpos que habitan en América Latina, el giro decolonial pone de relieve que no existe modernidad sin colonialidad, ni capitalismo sin extractivismo (p.16)

5 Cabe diferenciar el extractivismo de la extrahección que implica que "el proceso extractivista envuelve violación de derechos y violencia contra seres humanos que habitan en las comunidades afectadas. Se <arranca> los recursos naturales imponiéndose con violencia, quebrándose el marco de derechos y violándose los derechos humanos y de la naturaleza" (GROSFOGUEL, 2016, p.126). 
Por consiguiente, la decolonialidad ejerce para el caso una doble actuación: interpretar los vínculos de explotación/apropiación de los territorios; por otro lado, dar luz a las luchas no violentas, a otras maneras de interactuar con el mundo. En este punto, la propuesta implica la gestación de un programa sociopolítico-ambiental que defienda los territorios protegidos en tanto movimiento y acción colectiva como reacción -social e ideológica- donde prime la movilización y la diversidad de voces (ORTEGA SANTOS y OLIVIERI, 2017). En consecuencia, siguiendo a Guha (2000), la preocupación ambiental termina por concentrar sus esfuerzos en la democracia como movilización ciudadana y toma de conciencia política. De eso se tratan los casos que expondremos en la presente investigación.

Movilizaciones y luchas que se ven plasmadas también en los medios de comunicación que, de forma más o menos eficiente, realizan las coberturas sobre este tipo de acciones sociales. Los estudios decoloniales advierten en los medios no solo la difusión de valores, hábitos y sistemas de creencias (Grosfoguel, citado en VALENCIA, 2012); sino también espacios de lucha y resistencia complejos no exentos de contradicciones. La comunicación implica la construcción de sentidos que, de manera sistemática, se construyen y se negocian. La propia definición encierra una multiplicidad de significados. Como sostiene Thompson (1998, p.36), la comunicación es entendida como una actividad social que implica la producción, transmisión y recepción de formas simbólicas.

En este contexto, los medios desempeñan un papel primordial al ser concebidos como un fenómeno social cuyas formas simbólicas se plasman en contextos culturales e históricos precisos. La comunicación, por lo tanto, siempre "forma parte de contextos sociales estructurados de varias formas y que, a su vez, tienen un impacto estructural en los actos comunicativos" (p.26). En este sentido, el proceso comunicativo resulta trascendental en la constitución de una cultura.

En el mismo orden, la comunicación de riesgos ambientales implica un análisis sobre cómo la información es transmitida hacia la población, cuál es la percepción del público sobre los conflictos ambientales. De ahí el hecho de que exista una comunicación de riesgos tanto convencional como simbólica. La primera refleja el uso de los términos sobre el manejo de los riesgos ambientales, concentra los esfuerzos en la transferencia de saberes técnicos y de información científica a un lenguaje coloquial; mientras que la segunda, se focaliza en el 
discurso político y sus implicancias a la hora de informar sobre cuestiones de riesgo ambiental (KRIMSKY y PLOUGH, 1988).

En definitiva, en el presente artículo, partiendo de los supuestos establecidos desde el inicio de este apartado se trabajará tanto con el Diario Clarín como con el Diario La Nación, en tanto fuentes históricas de conocimiento sobre el pasado reciente y sus repercusiones culturales. Con el objetivo de indagar cómo estos periódicos construyen y contribuyen a legitimar miradas acerca de la relación que se establece entre el discurso político-social, las imágenes sobre la naturaleza, los recursos naturales y los sujetos que interactúan sobre cada territorio en disputa.

\section{Narrativas del conflicto socioambiental en Gastre, Chubut (1986- 1996)}

En octubre de 1986 se registra la primera acción colectiva en oposición al proyecto de la Comisión Nacional de Energía Atómica de instalar un sumidero nuclear en Chubut. El MACH a partir de este momento, como movimiento socioambiental, fue progresando paulatinamente y consolidándose a través de acciones de lucha no violenta. Los encuentros de discusión, debate y concientización se realizaban en escuelas locales; también se difundía la información que recopilaban en esas charlas y con panfletos; se explicaban los perjuicios de estas actividades para el medio ambiente y para la comunidad de manera clara y concreta. Asimismo, se dictaban conferencias a nivel nacional e internacional que permitieron divulgar la problemática. Estas acciones fueron incrementando el caudal de asambleas que se gestaban y, al mismo tiempo, permitían declarar municipios "no nucleares" dentro de la Patagonia consiguiendo la adhesión tanto de concejales como de intendentes locales.

El debate antinuclear no dio tregua, por el contrario, continuó vigente durante los diez años que siguieron al emblemático octubre de $1986^{6}$, donde se consiguió frenar el proyecto por diez años. Sin embargo, y pese a todos los esfuerzos, en 1996 la Comisión de Energía de Diputados de la Nación aprobó la instalación del basurero nuclear en Argentina. Fue el punto de inflexión por el

\footnotetext{
6 Para profundizar se recomienda revisar el artículo "La construcción de nuevas identidades socioambientales en la Patagonia Argentina frente a la amenaza nuclear en la prensa gráfica nacional (1986-1996)”. Revista de Paz y Conflictos, Vol.12 (2), 111-133.
} 
cual las organizaciones ambientalistas convocaron a una manifestación general, que tuvo como epicentro la localidad de Gastre, con el fin de oponerse nuevamente a este proyecto. Entre los convocados se destacaron el MACH, SER, la Fundación Patagonia Natural, RENACE, la Fundación para la Defensa del Ambiente (FUNAM), y la filial argentina de la ONG internacional Greenpeace (PIAZ, 2015).

La prensa nacional no descuida el evento, pese a la polarización de intereses que conlleva la problemática, brindando legitimidad tanto a la discusión como a las diversas posturas presentes en la discusión. Como mencionan Guzmán y Madrigal (2012), esta actitud mediática permite advertir los manejos en torno a los recursos naturales, al cuidado de la naturaleza y las luchas que se entablan entre los diversos grupos sociales involucrados en los conflictos socioambientales.

Así, el análisis de los periódicos revela cómo se proyecta la interacción entre la sociedad humana y la naturaleza, puesto que ofrecen una consideración particular a la situación que destacan en sus páginas, como también a los actores sociales que presentan y las voces que eligen mencionar. De esta manera, se comprende que el género informativo implique un contrato de lectura particular y diferente que debe incluir información certera, precisa y confiable. Por consiguiente, las noticias y crónicas permiten comunicar algunas visiones de mundo, como también intervenir sobre las creencias, los sentimientos y las opiniones de los lectores (WHITE, 1998, 2006).

El análisis de los diarios Clarín y La Nación permite detectar las diferentes voces que cada uno de los matutinos privilegió al momento de cubrir este caso. En consecuencia, se registra que Clarín presenta como voces autorizadas a: gobernador, diputados, titular de la CNEA y a Greenpeace. Por el contrario, La Nación da a conocer la palabra de: legisladores, gobernador, presidente del Movimiento Antinuclear del Chubut, estudiantes, vecinos, artistas, secretaria de Recursos Naturales, presidente de la Junta vecinal y titular de la CNEA.

Hay que mencionar, además, La Nación presenta una mayor heterogeneidad de voces en su cobertura. Se señalan las declaraciones de políticos/funcionarios, activistas y protagonistas. A esta sumatoria de testimonios, se incluye la voz de personalidades destacadas de la cultura para complementar la información al respecto -expresando la diversidad de posturas 
provenientes de diversas esferas-. Por lo que refiere a Clarín, su análisis se presenta más acotado dado que únicamente se puede advertir la voz de los políticos/funcionarios y de los activistas. En vista de que el diario que mayor cobertura otorgó al acontecimiento fue Clarín, pese a ello, ubica como principal portavoz del reclamo a la ONG Greenpeace, corriendo a un margen las acciones de otros activistas principales del conflicto como el presidente de la Junta Vecinal. De manera simultánea, brinda un espacio considerable al desarrollo de las posturas de los funcionarios de turno, privilegiando el discurso de representantes oficiales. Como resultado parcial se advierte que el diario que presenta mayor cobertura sobre el evento es el que, paradójicamente, menos actores sociales expone. La Nación se posiciona como el matutino donde se encuentran las notas más extensas y cuantiosos testimonios de los diferentes actores sociales presentes en el conflicto. Revelando un tratamiento más exhaustivo y una polifonía de expresiones.

Se pueden identificar una gran diversidad de asuntos vinculados con la problemática, caracterizados en su inmensa mayoría por el antagonismo que presentan los actores sociales involucrados y las posturas que cada uno defiende: la CNEA y los pobladores locales; funcionarios y pobladores locales.

Uno de los aspectos fundamentales para destacar es que las acciones de resistencia que se desarrollaron en la Patagonia establecieron una discusión directa sobre el problema, poniendo en relieve los procesos democráticos e incorporando a diferentes sectores de la sociedad al debate. Esto permitió ofrecer un lugar central a los protagonistas del conflicto, los pobladores locales. Como actores sociales fueron claves en la exposición e instalación del caso en la opinión pública, tal y como señalara Habermas (1973)

se puede construir algo así como la opinión pública, cuya entrada está fundamentalmente abierta a todos los ciudadanos. En cada conversación en la que los individuos privados se reúnen como público se constituye una porción de espacio público. [...] Los ciudadanos se comportan como público, cuando se reúnen y conciertan libremente, sin presiones y con la garantía de poder manifestar y publicar libremente su opinión, sobre las oportunidades de actuar según intereses generales. En los casos de un público amplio, esta comunicación requiere medios precisos de transferencia e influencia: periódicos y revistas, radio y televisión son hoy tales medios del espacio público (p.61) 
Al tiempo que, promovieron la conformación de movimientos integrados por figuras pertenecientes a diversos estratos, con diferentes edades, experiencias, recorridos de vida y formaciones, mediante el establecimiento de asambleas y reuniones vecinales, foros y charlas. Transformando, de esta manera, el proyecto de la CNEA en una disputa pública. Estas acciones tuvieron un impacto considerable en la resolución del conflicto y ocuparon un espacio de significativa visibilidad en la esfera pública gracias a la cobertura mediática que alcanzó.

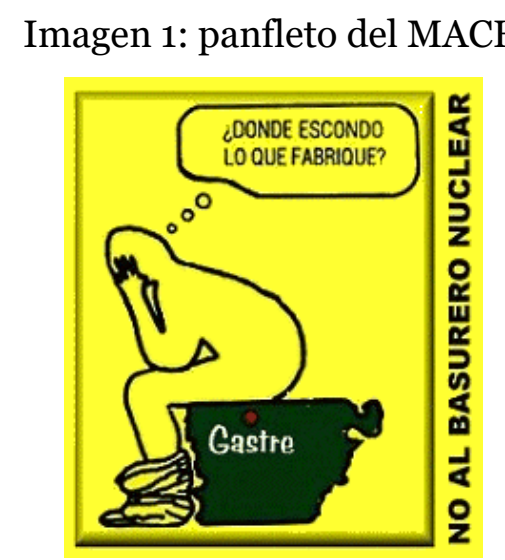

Fuente: Movimiento Antinuclear del Chubut7

Un año más tarde -marzo de 1997- la CNEA anuncia oficialmente la desactivación de esta iniciativa: "los pobladores de Gastre han recibido muy bien la noticia porque es la confirmación de que en la Sierra del Medio no se va a construir el basurero nuclear”, así lo declara el presidente de la Junta Vecinal, Héctor Rubén Paira. No queda duda que esta resolución es consecuencia de las acciones sociales de resistencia "es uno de los efectos de la permanente movilización y, en especial, la del año pasado”, asegura Paira al Diario La Nación.

No obstante, y pese a esta decisión, algunos ambientalistas como Roberto Rodríguez Pombo -titular de la Sociedad Ecológica Regional- todavía se mostraba

\footnotetext{
7 Las imágenes que fueron utilizadas a lo largo de esta lucha, para el caso de Gastre, no pueden ser consideradas únicamente como ilustraciones. Por el contrario, son elementos expresivos complejos que difunden los entramados centrales del discurso de resistencia que se estaba desarrollando durante el conflicto. En tal sentido, son documentos sociohistóricos y socioculturales, como ideológicos, informativos y comunicativos de trascendencia. Las imágenes que acompañan este artículo cumplen, por un lado, con una función conativa vinculada a la persuasión. Es decir que, el objetivo de éstas es el de convencer al público receptor sobre la problemática que acapara la atención de la comunidad. Por el otro lado, también cumplen una función fática ya que logran captar la atención del observador marcando la importancia de lo que está en juego. Sin embargo, no se puede tampoco eludir la función referencial que tienen los afiches elaborados por la comunidad patagónica bajo la cual se informa a la sociedad en su conjunto los peligros que traen aparejados las actividades que se intentan desarrollar en el territorio.
} 
escépticos y desconfiados frente a la declaración de la CNEA. Afirmaban que "antes de este anuncio, la propia CNEA había dicho en reiteradas veces que el basurero estaba desactivado. ¿Por qué debería de ser cierto ahora?”. Su preocupación es la de muchos que consideran que la privatización ${ }^{8}$ de las centrales nucleares, proyecto que integra el paquete de medidas similares aplicadas a otros ámbitos tomadas por el gobierno de turno, implicaría la pérdida del control directo de la Comisión Nacional de Energía Atómica9.

En abril de 1997, tanto en Clarín como en La Nación, figuran referencias sobre el caso: en el primero, se informa que el Senado aprobó la ley para privatizar las centrales atómicas que permite la instalación de repositorios nucleares, pero no fija lugares para construirlos. El matutino destaca el apuro con que fue tratado y aprobado este proyecto; en el segundo, el diario informa que esta ley traspasa la responsabilidad a las provincias escindiendo de responsabilidades al Estado Nacional. Nuevamente no se discuten los alcances de fondo de esta normativa y los riesgos que conlleva su aprobación.

La situación lejos de encausarse positivamente se ennegrece con la publicación de una investigación periodística realizada dos años después por el diario La Nación. El medio asegura haber tenido acceso a documentos reservados donde hallaron incongruencias entre fechas y actividades en la región previas a la gran movilización de Gastre de 1996. De esta manera, luego de la suspensión del proyecto de la CNEA -en 1990- se registraron movimientos de 36 toneladas de cargamentos hacia Chubut, que contenían materiales como baritina (que es un tipo de sellador empleado para repositorios nucleares), como también dudosos

\footnotetext{
${ }^{8}$ Durante la década de 1990 el Gobierno Nacional, encabezado por el presidente Carlos Menem, sancionó diversas leyes que tuvieron como objetivo final atraer inversiones hacia la actividad minera. La que más se destaca es la "Ley de Inversiones Mineras" ( $\mathrm{N}^{\circ}$ 24.196), que traía aparejado, en teoría, beneficios tales como:

estabilidad fiscal; deducciones en el impuesto a las ganancias; amortización acelerada de inversiones al efecto del impuesto a las ganancias; avalúo y capitalización de reservas, sin efectos impositivos; exención de derechos, gravámenes y tasas aduaneras para importación de bienes de capital, equipos e insumos para desarrollar proyectos mineros; fijación de un tope de $3 \%$ del valor boca mina para el cobro de regalías, entre otros. Asimismo, fomentó la participación de empresas privadas en la inversión de riesgo que antes asumió el Estado. Este fue el escenario que habilitó, entonces, el incremento de la actividad privada tanto nacional como internacional en el país vinculada a proyectos de prospección y explotación minera en Argentina (Wagner,2014, pp. 8788).

9La decisión de emplazar el basurero nuclear en Gastre es resultado de un estudio llevado adelante en 198 posibles regiones. Así, Sierra del Medio es la zona seleccionada con un batolito granítico con $28 \mathrm{~km}$ de largo y $8 \mathrm{~km}$ de ancho que sería el cementerio de 75 metros cúbicos de residuos radiactivos por diez mil años, envasados en una matriz vítrea fundida en recipientes de acero inoxidable y cubierto de plomo para prevenir la erosión.
} 
traslados de personal hacia la zona de minas de uranio de Los Adobes $^{10}$. La gravedad del caso se incrementa con el hallazgo de cuatro cuerpos en las inmediaciones de las minas que presentaban características propias de intoxicación con hexafluoruro de uranio. Pero ¿cuál es el punto de intersección entre Gastre y Los Adobes? La sospecha más fuerte establece que el basurero nuclear que se intentó evitar en Gastre pudo haberse construido igual en zonas aledañas a este poblado, aunque la Comisión Nacional de Energía Atómica lo negara.

En esta investigación periodística, además, se informa que estas actividades poco usuales se detectaron nueve años después del cierre definitivo de la mina de uranio. Sin embargo, los documentos encontrados evidencian órdenes de compra, recibos, contratos y mapas generados por INVAP (empresa de Investigaciones Aplicadas Sociedad del Estado) durante 1990. Entre los datos más relevantes La Nación subraya dos:

La orden de entrega número 1985 del 12 de noviembre de 1990, según la cual el Invap compra a la empresa neuquina Carlos Suhr 36 toneladas de bentonita para ser entregadas en el parque industrial de Trelew, en forma inmediata y pago contado anticipado. La bentonita es el sellador utilizado en los repositorios de residuos nucleares y, según fuentes consultadas, "treinta y seis toneladas sólo pueden ser necesarias para sellar un basurero de grandes dimensiones". El segundo, la orden de entrega número 2045 del 20 de noviembre de 1990, por la que el Invap contrata a la empresa Turismo Buttini de San Rafael, Mendoza, para trasladar a 19 personas desde la capital provincial hasta la mina de uranio de Los Adobes, en Chubut. Al momento de contratar este servicio, hacía 8 años que la mina estaba cerrada y sin funcionamiento (Diario La Nación, 05/07/1999)

Frente a esta incertidumbre, el vocero del INVAP, admitió no tener respuestas concretas. Esto alerta a las organizaciones ambientalistas sobre estos extraños movimientos ejecutados dos semanas antes de darse a conocer el documento por el cual, el presidente argentino Carlos Menem, aseguraba la cancelación del proyecto del basurero nuclear de Gastre.

El vicepresidente de la Fundación Patagonia Natural, José María Musmeci, refuerza la idea inicial al decir que "muchos creen que en la Patagonia se guardan en secreto residuos nucleares”. Del mismo modo, admite que fueron

10 La mina de uranio Los Adobes fue explotada durante la última dictadura cívico-militar argentina y queda a 40km de la localidad de Paso de los Indios. 
numerosas las advertencias de los pobladores que le informaban la aparición de camiones sospechados de cargar material nuclear. Al respecto sostiene que, "unos llevaban mercadería corriente y otros, si bien eran de la CNEA, iban con todo en regla para Pilcaniyeu [localidad a $300 \mathrm{~km}$ de Gastre] o Bariloche. Pero a algunos de esos camiones se los tragó la tierra, y nunca los pudimos encontrar”.

El poblado de Paso de los Indios se encuentra en el mismo cordón donde se pensaba instalar el basurero nuclear de Gastre. Allí se encontraron los cuatro cuerpos en 1993. Pese a que la mina de uranio de Los Adobes se había dejado de explotar en 1981 habían quedado en la zona más de 55 mil toneladas de residuos radiactivos. A $40 \mathrm{~km}$ del lugar se encuentra otra mina de uranio, Cerro Solo, y la CNEA asegura que ese fue el destino del material y personal detectado en los documentos encontrados. Sin embargo, se percibe una contradicción: la CNEA no figura en esos escritos.

Con respecto a las cuatro muertes, la investigación de La Nación detalla que

el primer cadáver fue encontrado unos $60 \mathrm{~km}$ al norte del pueblo, en las instalaciones de la mina; [el segundo] apareció 4 días después; [el tercero] 15 días después y cuando se creía que la serie parecía terminada, fue hallado el cuarto muerto" (Diario La Nación, 06/07/1999)

Tanto la fiscal que intervino en el caso, la policía y el juez resaltaban con extrañeza este descubrimiento, demasiadas muertes en un poblado con muy poca gente. Luego de numerosas investigaciones, no exentas de dudas y contradicciones, se dictaminó que al menos dos de los cadáveres presentaban cristalización pulmonar, causada por contaminación con uranio. El doctor Juan Carlos Giménez, especialista en radiopatologías del Instituto de Radiomedicina y Seguridad, consultado por el diario explicó que:

El uranio se encuentra en la naturaleza y hasta 90 microgramos, en un hombre de unos 70 kilos, es tolerable. Pero cuando el uranio se enriquece, se transforma en un agente radiotoxicológico que al incorporarse por vía inhalatoria puede producir lesiones graves. El hexafluoruro de uranio, al penetrar en el organismo, reacciona frente al agua y genera ácido fluorhídrico, causante de irritaciones y edemas agudos de pulmón. Eso se llama cristalización pulmonar (Diario La Nación, 06/07/1999) 
El diario El Patagónico también se hace eco de esta noticia, y subraya como dato trascendental en la investigación de La Nación que lo más extraño del caso es que:

hay pruebas documentales de que hubo traslados de personas a minas abandonadas, de que se concentraron en la zona cantidades inusuales de selladores para depósitos radiactivos y de que después de eso hubo muertos con síntomas propios de una intoxicación con hexafluoruro de uranio, aunque el Invap no puede dar explicaciones sobre eso y la Comisión Nacional de Energía Atómica lo atribuye a tareas cuyas constancias, hasta el momento, no aparecieron (El Patagónico, 8/11/2016)

De este modo, La Nación concluye su artículo diciendo que "el basurero que se iba a construir en Gastre parece haber pasado al olvido, pero un manto de duda sigue cubriendo toda la cuestión". La ausencia de informes oficiales precisos prolonga las sospechas, generan incertidumbre y habilitan las más aventuradas conjeturas sobre estos casos.

\section{Narrativas decoloniales en Esquel, Chubut (2000-2003)}

Examinaremos ahora otro resonante ejemplo de conflicto socioambiental, que aconteció desde la segunda mitad de la década de los noventa hasta las dos primeras décadas del nuevo milenio, en Argentina. Consideramos significativo hacer mención este tipo de casos que han acaparado, de una u otra manera, la atención de la esfera pública desafiando diferentes medidas de acción de resistencia de grupos sociales en defensa de la naturaleza, que han puesto en entredicho la relación sociedad-ambiente.

Frente al creciente surgimiento de los conflictos socioambientales en Argentina, se destacan aquellos vinculados a los proyectos extractivos de minería a cielo abierto. Como sostiene Wagner (2016), el rechazo a estas iniciativas consolidó la emergencia de movimientos sociales y la legislación restrictiva en, por lo menos, siete provincias de nuestro país. En este sentido, la década de los noventa se presenta como el contexto primordial con la llegada de inversores extranjeros a la actividad y la modificación del Código de Minería que privilegia la inserción de empresas privadas incrementando la explotación minera en el país.

El primer caso de instalación de un megaproyecto minero lo evidencia la Mina Bajo de la Alumbrera, ubicada en la provincia de Catamarca al noroeste del 
país, que comienza su explotación en 1997. Así lo anunciaba el diario Clarín el o1 de noviembre, informando que se trataba de la inauguración de la mina de cobre más grande de Argentina y una de las diez más imponentes del mundo. El proyecto estaba a cargo de la Minera Alumbrera Limited, asociación de capitales de Canadá y Australia. Como manifiesta Wagner (2016)

hasta la instalación de este proyecto, en la provincia de Catamarca, [Argentina] no tenía antecedentes históricos de grandes emprendimientos mineros. Hasta la reforma del Estado en 1990, el Código Nacional de Minería representaba a los recursos naturales no renovables como el reaseguro de la soberanía nacional. Entre 1930 y 1980 la minería y metalurgia fueron, casi exclusivamente, un tema de militares. Fue recién en los primeros años de la década de 1990 cuando el gobierno nacional promovió, a partir de un conjunto de leyes, la desregulación de la minería, permitiendo la elaboración de importantes proyectos de inversión al sector privado externo (p.91)

Si bien es cierto que La Alumbrera fue el primer proyecto de megaminería, su instalación al principio no condujo a un rechazo profundo ${ }^{11}$. Empero, el caso de Esquel (Chubut) fue pionero en resistir en el 2002 a la instalación del proyecto minero de extracción de oro. Como veremos, sentó un precedente sin igual; primero, para la consolidación del movimiento socioambiental argentino; segundo, para la producción minera en el país. Una vez más, la Patagonia ${ }^{12}$ se levanta para defender sus recursos y calidad de vida: "Esquel se transformó en el ícono del "No a la Mina" en Argentina, colocando un manto de incertidumbre sobre los potenciales riesgos de los proyectos mineros metalíferos, especialmente sobre aquellos que utilizaban cianuro para separar el mineral de la roca" (WAGNER, 2016, p.93).

Décadas después de la multitudinaria movilización de Gastre, los pobladores locales de Chubut conforman, como ya se mencionó, la Asociación de Vecinos Autoconvocados de Esquel (AVAE) para encabezar la lucha no violenta:

\footnotetext{
${ }^{11}$ Sin embargo, los proyectos mineros que quisieron desarrollase con posterioridad a la instalación de La Alumbrera sí enfrentaron a la resistencia local. Wagner (2016) sostiene que, en parte, este giro se debe a "una desilusión en cuanto al "derrame de beneficios" que La Alumbrera había prometido y no se reflejó en las localidades cercanas al proyecto", por otro lado, también se adjudica esta reacción a las diferentes y numerosas experiencias que se detectaron en otras provincias frente a esta misma actividad.

${ }_{12}$ Dentro de la Patagonia, otro caso relevante fue el de Ingeniero Jacobacci (Río Negro), donde la empresa Pan American Silver se propuso la extracción de oro y plata. Sin embargo, no prosperó dada la prohibición del uso de cianuro y mercurio en las actividades mineras presentes en la ley que promulgó el gobierno provincial, luego de las repercusiones sociales que trajo aparejado el proyecto.
} 
"En Esquel se realizaron manifestaciones masivas, logrando la postergación de la audiencia pública del proyecto minero e impulsando un plebiscito en el cual el 81\% de los pobladores de Esquel votaron por el "No a la Mina13" (Wagner, 2016, p.94).

Imagen 2: Manifestación "No a la mina"

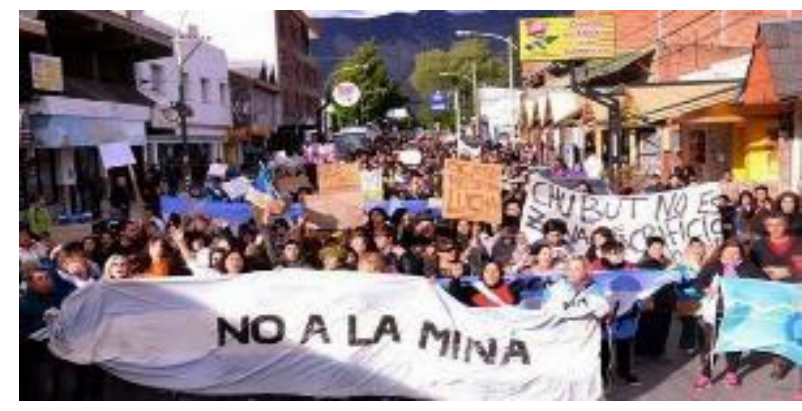

Fuente: Observatorio de Conflictos Mineros en América Latina

Weinstock (2006) advierte que "los vecinos autoconvocados se gestaron al calor de la creciente indignación popular generada por la omisión de datos sobre un proyecto minero, en especial, el ocultamiento sobre la utilización de cianuro en el proceso de extracción” (p.1). En el año 2002 la población de Esquel tomó conocimiento de manera definitiva de la inminencia del inicio de la explotación minera en el Cordón Esquel. El Gobierno de la Provincia, de la mano del por entonces Director de Minería y geólogo Guillermo Hughes, hizo públicas las intenciones de la Minera el Desquite S.A. (adquirida ese mismo año por Meridian Gold de Canadá) de comenzar la etapa de explotación del yacimiento de oro y plata localizado a $6,5 \mathrm{~km}$ de la ciudad, y cuya exploración venía realizándose desde fines de la década de 1990. Al respecto el Diario La Nación resalta que:

Según los estudios de prefactibilidad realizados en el yacimiento, la mina de Esquel, que será explotada a cielo abierto, tendrá una vida útil de diez años y su capacidad de producción posee un piso asegurado de 300.000 onzas de oro anuales (aproximadamente 9 toneladas) En la etapa de construcción de la mina se crearán 700 puestos de trabajo, y durante los diez años de operación se sumarán otros 500, entre directos e indirectos. (La Nación, 05 de abril de 2002)

Las promesas para incrementar el trabajo, en una provincia que ha sufrido numerosos reveses en su estructura socioeconómica no se hacen esperar, al igual que sucedía en el caso de Gastre. Como consecuencia, grupos de vecinos y

${ }^{13}$ https://noalamina.org/ 
profesionales de la Universidad Nacional de la Patagonia -durante junio a noviembre- llevaron a cabo numerosas charlas y mesas de debate sobre la problemática. Asimismo, visitaban escuelas de nivel primario y secundario con el objetivo de concientizar a los jóvenes de la situación, compartiendo la información a la que se tenía acceso.

En octubre de 2002 se iniciaron las asambleas vecinales integradas por los diversos sectores involucrados en el conflicto. De modo que, el o4 de diciembre se lleva adelante la segunda asamblea donde se pronunció por unanimidad (hubo 600 asistentes) el "No a la mina”. Este fue el punto de partida de diferentes acciones de lucha no violentas por parte del pueblo de Esquel, a saber: información en mesas instaladas en la vía pública, pintadas en la calle frente a la oficina de la minera, murales alegóricos, festivales artísticos, charlas en otras localidades que también manifestaron su rechazo al emprendimiento y cuatro movilizaciones con la participación de un número creciente de opositores a la mina. Este movimiento socioambiental ha conseguido atravesar transversalmente la comunidad, puesto que está integrado por personas de todos los sectores sociales, profesionales, comerciantes, prestadores turísticos, desocupados, trabajadores, jóvenes, etc. En atención a lo cual, se sentó un precedente histórico que habilitó el debate público a escala local, provincial y nacional. El mismo diario advierte que:

\begin{abstract}
Según lo previsto, se utilizarán 600 hectáreas del Cordón Esquel donde se emplazará una planta de tratamiento que procesará 3000 toneladas diarias de mineral. Las expectativas comerciales de la minera El Desquite son importantes y buscan consolidar la rentabilidad de la empresa. Las previsiones indican que la extracción alcanzará los 10 gramos de oro y 17 de plata por tonelada de material procesado. Sin embargo, Meridian debe, antes de iniciar los trabajos, sortear algunos obstáculos. En primer lugar, necesita la aprobación del estudio de impacto ambiental que está en manos del Ministerio de la Producción del gobierno provincial (La Nación, 23 de enero de 2003)
\end{abstract}

En este sentido, la empresa minera tiene que, además, sortear las preocupaciones concretas planteadas por los habitantes del lugar con relación al uso del agua y la contaminación con cianuro, temas que fueron tratados en la audiencia pública realizada el 29 de marzo de 2003. Situación que acontece, como señala el matutino, en medio de

vaivenes políticos y controversias con los pobladores cordilleranos, los trabajos de exploración para evaluar la futura 
explotación minera -que abarca los denominados Cordón Huemules, Cholila, Lelleque y Nahuelpan- continúan en las 142.00o hectáreas de esta región de bosques y lagos. "Esto no quiere decir que todos estos sectores se conviertan en yacimientos. Se realizan trabajos de exploración para analizar la posibilidad de encarar diferentes emprendimientos. Este es un negocio de alto riesgo económico", dijo Natalia Moscardi, gerente de Recursos Humanos de la empresa minera (La Nación, 23 de enero de 2003)

El superintendente de operaciones de la minera, José de Castro, confirmaba la utilización de la sustancia tóxica en la explotación. Asimismo, aseguraba que los desechos sufrirían un proceso de destrucción que impediría la contaminación del ambiente. Asegura, también, que el agua empleada es devuelta al sistema para su reutilización. Una falacia más de esta historia.

Todas las semanas más de 3 mil personas se congregaban en las calles de Esquel al grito de "No a la mina", con sus pancartas explicativas denunciando la situación y alertando los peligros que implica el desarrollo del emprendimiento minero en la zona. Diversos sectores sociales se ven involucrados en el conflicto, actores sociales como el gobierno nacional y provincial, los protagonistas que son los pobladores locales, los empresarios mineros, entidades internacionales: “parece que en Esquel la situación es especialmente riesgosa: la mina está apenas a siete kilómetros del aeropuerto y a veinticinco de la ciudad y se argumenta que el cianuro se filtrará en los ríos y, en poco tiempo, lagos y bosques padecerán su efecto", se señala en La Nación (20 de marzo de 2003). Las autoridades rechazan las protestas de los habitantes e intentan convencerlos que se trata de una falsa alarma. A su vez, el Ministerio del Interior de la Nación, indica que la superficie por explotar abarca unas mil hectáreas. En el yacimiento se han identificado 16 venas de cuarzo portadoras de oro y que la explotación durará diez años.

En otro orden, la empresa respondió a las protestas asegurando que "el aire de la ciudad seguirá siendo puro". No obstante, la alerta sobre los riesgos ambientales que ocasionaría la instalación de la mina lo dio Greenpeace: "La minería de oro con lixiviación de cianuro -señaló la organización internacional, citada en el informe del Ministerio del Interior- no es una práctica sustentable; por el contrario, depreda los recursos naturales no renovables y deja un eterno legado de contaminación" (La Nación, 20 de marzo de 2003). Así, frente a las manifestaciones de repudio en todo Chubut (El Bolsón, El Hoyo, Lago Puelo, 
Esquel, El Maitén, Epuyén y Cushamen), la Legislatura provincial tuvo que postergar por 90 días el emprendimiento.

El 75\% del padrón participó de la consulta popular que realizó el gobierno provincial, dando como resultado 11046 votos en contra del proyecto y 2561 a favor. Con este resultado el gobernador, José Luis Lizurume, tuvo que anunciar la paralización del proyecto minero. A su vez, sostuvo que

ahora la empresa canadiense Meridiam Gold, propietaria de la mina de oro y plata "deberá reformular el proyecto, asegurar la no contaminación de las aguas, contratar otra consultora que convenza a la población y esperar la audiencia de impacto ambiental para poder eventualmente seguir adelante (Clarín, 26 de marzo de 2003)

La respuesta de la población fue contundente, validando una vez más, el interés público en este tipo de conflictos relacionados a las interacciones entre sociedad y naturaleza, desafiando la articulación de redes donde se discutieron temas, demandas, posibilidades y peligros

Entidades ecologistas y científicos revelaron que el cianuro
utilizado en grandes cantidades puede contaminar el ambiente y
el agua. Entonces la comunidad de Esquel comenzó a
movilizarse. Así, nacieron los "Vecinos Autoconvocados" que
realizaron varias marchas contra la explotación minera. Y
obligaron al Concejo Deliberante a convocar a un plebiscito y a
prohibir el uso de cianuro en el ejido municipal (Clarín, 26 de
marzo de 2003)

Al respecto, Alejandro Corbele y Pablo Quintana, vecinos del lugar señalaron que "los vecinos hemos denunciado los problemas de contaminación de agua, los riesgos de la utilización de cianuro, los escombros y desechos tóxicos, como así también las leyes nacionales que benefician a las mineras extranjeras” (Clarín, 22 de agosto de 2003). Mientras tanto, la única preocupación de la empresa minera, frente a esta creciente demanda y contundente respuesta por parte de la población contra la explotación en la zona, implicaba calmar a sus accionistas. De esta manera, era manifestado su pesar en la página web de la empresa

Meridian Gold actualmente no está haciendo ningún trabajo de explotación en Esquel y las actividades se han detenido con respecto a este proyecto debido a las inquietudes de la comunidad. En el 2003, la empresa contrató a Business For Social Responsability (BSR) para ayudarle con sus esfuerzos en las relaciones con la comunidad de Esquel. El informe BSR fue entregado a la comunidad de Esquel en agosto y Meridian Gold está analizando el informe y las inquietudes de los ciudadanos 
locales. Meridian Gold continúa evaluando las opciones relacionadas con este proyecto para resguardar de mejor manera los intereses de los accionistas (En WEINSTOCK, 2006, p. 5)

En el mismo sentido, la empresa responsabiliza a los habitantes de Esquel por el esfuerzo frustrado de desarrollar el proyecto minero en la zona "la falta de un compromiso integral con la comunidad de Esquel (...) factor que influyó fuertemente en los miembros de la comunidad al momento de decidir no apoyar el proyecto de la mina y para dedicar toda su energía al movimiento opositor" (En WEINSTOCK, 2006, p. 5). Lo expuesto hasta el momento da cuenta de los diversos criterios que involucra la discusión sobre conflictos socioambientales, donde resulta fundamental entender las continuidades, disrupciones, contradicciones y omisiones que ejercen los actores sociales involucrados desde el comienzo. Habilitando la definición de estos conflictos como controversias socioambientales dinámicas que se plasman en la opinión pública.

\section{Discusión y palabras finales}

En los casos seleccionados se visibiliza la existencia de un discurso que nace de las asambleas populares que podemos denominar discurso de resistencia; frente a la postura de políticos, funcionarios y empresarios que nombraremos discurso del progreso. Ambos contraponen intereses diferentes y antagónicos. El primero, involucra acciones colectivas de protesta autoconvocadas, pacífica y actividades simbólicas. Esta metodología de lucha experimentó una creciente visibilidad en los espacios públicos que generó un impacto positivo al conseguir su objetivo primordial: por un lado, defender los recursos naturales patagónicos; por el otro, la calidad de vida de sus habitantes, tanto para las generaciones presentes como futuras, resistiendo la instalación del basurero en Gastre y el desarrollo minero en Esquel. En tal sentido, ambos ejemplos son claros para entender la consolidación de la primera expresión del activismo ambiental patagónico (WALTER y URDAKI, 2014), marcando una impronta a nivel regional, con proyección nacional y resonancia internacional.

El discurso del progreso, en cambio, implica una lógica instrumental y hegemónica a disposición de variables económicas, y políticas disfrazadas de desarrollo tecnológico y progreso. En este punto la política y la naturaleza no se encuentran en polos opuestos (LATOUR, 2013), dado que la primera se define también en su relación con la segunda en la que "cada rasgo, cada propiedad y 
cada función dependen de la voluntad polémica de limitar, reformar, fundar e iluminar la vida pública” (p. 17). En consecuencia, la irrupción de los actores sociales en el escenario de conflicto, y su intervención en la discusión, amplía la perspectiva de análisis, genera nuevos interrogantes y transforman medidas o decisiones técnicas en cuestiones sociales y políticas de gran envergadura, a través de la protesta social, el cuestionamiento, la activa participación ciudadana, el debate, de la creación de una identidad de grupo donde se privilegia un nosotros inclusivo -como forma concreta de expresión- donde se privilegia la horizontalidad y se construye un otro de exclusión. Siguiendo a Bauman (1990) esta distinción entre "nosotros" y "ellos" se relaciona con estar dentro o fuera de un grupo determinado. Ambas expresiones son totalmente opuestas entre sí, porque donde hay un sentimiento de pertenencia no puede existir el de exclusión, no obstante, sólo pueden entenderse en su confrontación.

Cabe destacar que es esa oposición la que contribuye a consolidar la cohesión e identidad de pertenencia del grupo, frente al inminente discurso falaz que aseguraba la estabilidad y prosperidad de las comunidades. La lucha, la movilización, la acción de los ciudadanos y el conflicto socioambiental cobran especial envergadura a partir de este hecho donde lo discursivo es asociado a la praxis.

En Chubut, las movilizaciones en rechazo al repositorio nuclear establecieron el surgimiento de organizaciones no gubernamentales (MACH y AVAE) y asambleas vecinales. Se promulgó la democratización del conocimiento en torno a temáticas, en principio, desconocidas para la mayoría de los patagónicos. Esto favoreció la toma de consciencia por parte de la ciudadanía que, en definitiva, fue la que activó y puso en funcionamiento la resistencia. En sintonía, en el caso de la actividad minera se presenta como una posibilidad de desarrollo económico y aparenta consolidar puestos de trabajo en detrimento de las condiciones de vida, la salud y el ambiente. Es un fenómeno multifacético y de gran complejidad, con puntos de intersección y características comunes. Lo cierto es que en esta clase de proyectos se esconde un mismo modelo de desarrollo y dimensiones sociales, ambientales, económicas, políticas y culturales para tener en cuenta en su análisis. En este sentido, la actividad minera compite con las actividades económicas/productivas de las zonas donde se asientan los proyectos. Esto, unido a los impactos ambientales, alerta a los pobladores locales y potencia 
la concientización de la ciudadanía sobre los riesgos que implica esta actividad generando un incremento de la protesta social.

La oposición a los dos proyectos se origina en dos localidades chubutenses, pero se expande y multiplica a nivel provincial. Se prolonga el conflicto, la preocupación, la discusión y las acciones concretas a un plano nacional e incluso internacional. Los reparos frente a las amenazas por el sumidero y la explotación minera procedieron de diferentes voces, desde estudiantes secundarios a expertos científicos; transitando franjas intermedias compuestas por periodistas, funcionarios, académicos $\mathrm{y}$, protagonistas indiscutibles de este hecho, los pobladores locales que pusieron en práctica diversas formas de intervención en el espacio público otorgando visibilidad y politizando el conflicto. De este análisis se desprende las características innatas de este tipo de movimiento social, su heterogeneidad, descentralización, interconexión y diversidad de formas de expresión. Así como su capacidad de gestar redes locales, provinciales, nacionales e internacionales.

La provincia de Chubut fue pionera en implementar modificaciones sustanciales en su carta magna en materia ambiental que le permitió presentar argumentos sólidos en las diferentes instancias de lucha. Podemos considerar estos casos patagónicos pioneros en establecer controversias socioambientales en Argentina. Fueron proyectos que defendieron su territorio, su tecnología, sus recursos naturales y económicos junto al bienestar propio con base en la resistencia. Identidades que se fueron estructurando de acuerdo con la construcción de valores y experiencias que no se diluyeron, por el contrario, se afianzaron fortaleciendo las luchas con mayor organización, conocimiento, transformándose en instrumentos nodales para materializar las demandas.

Los ejemplos expuestos a lo largo de estas páginas dan cuenta la diversidad de temáticas, el alcance geográfico de las problemáticas, las características comunes que unifican los reclamos sociales, las metodologías de lucha compartidas por los ciudadanos para llevar adelante la resistencia, las contingencias a las que se enfrentan y los resultados fructíferos a los que arribaron. Conflictos que -en algún caso aún no culminado, puesto que la lucha en Esquel continúa vigente- se han resuelto favorablemente para la ciudadanía, o bien se ha conseguido atenuar los daños y también detener las actividades. 
Revista Brasileira de História \& Ciências Sociais - RBHCS

Vol. $12 \mathrm{~N}^{\circ} 23$, Janeiro - Junho de 2020

Sin embargo, los conflictos socioambientales en Argentina persisten y todavía requieren de más y mejores formas de lucha, ya que el modelo dominante continúa vigente con cambios o retrocesos. Consideramos relevante, así, ofrecer un espacio al conocimiento de estos conflictos en torno a los cuales la participación ciudadana cobra trascendencia, se articula dando lugar a un ejercicio democrático -descentralizado y directo- que cuestiona el modelo de desarrollo económico hegemónico desde acciones pacíficas de resistencia.

\section{Bibliografía}

ADORNO, Theodoro y HORKHEIMER, Max. La Sociedad: Lecciones de sociología. Buenos Aires: Proteo, 1979

BAUMAN, Zigmund. Pensando sociológicamente. Buenos Aires: Ediciones Nueva Visión, 1990

BOBBIO, Norberto; MATTEUCCI, Nicola y PASQUINO, Gianfranco.

Diccionario de política. México: Siglo XXI, 1991

BOLADERAS CUCURELLA, Margarita. La opinión pública en Habermas.

Revista Análisi, nº26, 51-70, 2001

BRAUN, Bruce y WAINWRIGHT, Joel (2001). Nature, poststructuralims, and politics. En: CASTREE Noel y BRAUN Bruce (eds) Social nature, theory, practice and politics. USA-UK-Australia: Blackwell Publishing

BUCKLES, Daniel (ed). Cultivar la paz. Conflicto y colaboración en el manejo de los recursos naturales. Canadá: IDRC, 2000

CASTELLS, Manuel. Comunicación y poder. España: Alianza Editorial, 2009

COSER, Lewis. Nuevos aportes a la teoría del conflicto. Buenos Aires:

Amorrortu, 1970

GARCÍA, Ernest. Medio ambiente y sociedad: la civilización industrial y los límites del planeta. Madrid: Alianza Ensayo, 2011

GROSFOGUEL, Ramón. Del extractivismo económico al extractivismo epistémico y al extractivismo ontológico: una forma destructiva de conocer, ser y estar en el mundo. Tabula Rasa, $\mathrm{n}^{0}$ 24, pp. 123-143, 2016 GUDYNAS, Eduardo (2016). Teología de los extractivismos. Introducción a Tabula Rasa No 24. Tabula Rasa, $n^{0}$ 24, pp. 11-23, 2016 
Revista Brasileira de História \& Ciências Sociais - RBHCS

Vol. $12 \mathrm{~N}^{\circ} 23$, Janeiro - Junho de 2020

GUHA, Ramachandra. Environmentalism. A Global History. New York, Longman World history Series, 2000

HABERMAS, Jürgen. «Öffentlichkeit (ein Lexikonartikel) 1964», en Kultur und Kritik.

Francfort a.M.: Suhrkamp, 1973

KRIMSKY, Sheldon y PLOUGH, Alonzo. Environmental Hazards:

Communicating Risks as a Social Process. Dover: Auburn House Publishing Co, 1988

LATOUR, Bruno. Políticas de la naturaleza. Por una democracia de las ciencias. Barcelona: RBA Libros,2013

LEFF, Enrique. Ecología y capital. Racionalidad ambiental, democracia participativa y desarrollo sustentable. México: Siglo XXI, 1986

LEZAMA, José Luis. La construcción social y política del medio ambiente.

México: El Colegio de México, 2004

MADRIGAL, David y GUZMAN, Mauricio. Naturaleza y sociedad en San Luis

Potosí. Apuntes para una ecología política. En: DURAND, Leticia; FIGUEROA, Fernanda \& GUZMÁN, Mauricio (ed). La naturaleza en contexto: hacia una ecología política mexicana. México: UNAM, 2012, pp-95-136

MCQUAIL, Denis. Introducción a la teoría de la comunicación de masas. Barcelona: Paidós, 1994

NYGREN, Anja. Prólogo. En: DURAND, Leticia; FIGUEROA, Fernanda \& GUZMÁN, Mauricio (ed). La naturaleza en contexto: hacia una ecología política mexicana. México: UNAM, 2012, pp.11-20

ORTEGA SANTOS, Antonio y OLIVIERI, Chiara. Narrativas Coloniales de la Historia Ambiental. Un balance hacia la Decolonialidad como nueva epistemología. HALAC, 7(2), pp. 32-64, 2018

PARRA-ROMERO, Adela. ¿Por qué pensar un giro decolonial en el análisis de los conflictos socioambientales en América Latina?. En Revista Ecología Política, julio, pp-15-20, 2016

PAZ, Fernanda. Conflictos socioambientales, cultura política y gobernanza: la cooperación bajo sospecha en el distrito minero de Molango en el estado de Hidalgo. En: DURAND, Leticia; FIGUEROA, Fernanda \& GUZMÁN, Mauricio (ed). La naturaleza en contexto: hacia una ecología política mexicana. México: UNAM, 2012, pp. 65-94 
Revista Brasileira de História \& Ciências Sociais - RBHCS

Vol. $12 \mathrm{~N}^{\circ} 23$, Janeiro - Junho de 2020

PEET, Richard y WATTS, Michael. Liberation ecologies. Environment, development and social movement. Londres: Routledge, 2002 PIAZ, Agustín. Acciones de resistencia a la tecnología nuclear en la Argentina.

Revista Redes, $\mathrm{n}^{\mathrm{O}}$ 21, pp.111-140, 2015

RODRIGUEZ PARDO, Javier. El repositorio nuclear de Gastre. El movimiento social que impidió la instalación del repositorio de residuos radiactivos de alta actividad en la Patagonia. Buenos Aires: Proyecto Lemú,2007 ROJAS, Facundo y GALLARDO, Osvaldo. La historia ambiental en contextos de transformaciones. Contribuciones desde el centro del oeste argentino. En: ZAIDENWERG, C.; GARZA MERODIO, G.; PIQUERAS CÉSPEDES, R. y DALLA-CORTE CABALLERO, G (coord). Ciencias sociales, humanidades y derecho: cómo pensar el mundo latinoamericano. Barcelona: Universitat de Barcelona y Universidad Nacional Autónoma de México, 2017 SCRIBANO, Adrián. Movimientos sociales, acción colectiva y protesta social. Buenos Aires: UBA, 2005

SISMONDO, Sergio. Some social construction. Social studies of science, vol $23, \mathrm{n}^{0} 3,1993$

THOMPSON, John. Los media y la modernidad. Una teoría de los medios de comunicación. Barcelona: Paidós, 1998

VALENCIA, Juan Carlos. Mediaciones, comunicación y colonialidad: encuentros y desencuentros de los estudios culturales y la comunicación en Latinoamérica. Signo y Pensamiento, vol. 30, no 6o, pp. 156-165, 2012 WAGNER, Lucrecia. Conflictos socioambientales por megaminería en Argentina: apuntes para la reflexión en perspectiva histórica. Revista Internacional de Ciencias Sociales “Áreas”, nº 35, pp.87-99, 2016 WAGNER, Lucrecia. La lucha contra la contaminación y el saqueo: de movilizaciones en Mendoza a la unión de las reivindicaciones socioambientales en América Latina. En Revista História Unisinos, 12(3), pp 195-206, 2008 WALTER, Mariana, URKIDI, Leire. Anti-gold mining movements in Argentina (Esquel) and Chile (Pascua-Lama). ENGOV Working Paper, $\mathrm{n}^{0}$ 11, pp. 1-31, 2014

WEINSTOCK, Ana. No todo lo que (brilla) vale es oro. El caso del "No a la mina" de Esquel. Argumentos, no 7, pp. 1-22, 2006 
Revista Brasileira de História \& Ciências Sociais - RBHCS

Vol. $12 \mathrm{~N}^{\circ} 23$, Janeiro - Junho de 2020

WHITE, Peter. Telling Media Tales. The News Story as Rhetoric. Sidney:

University of Sidney, 1998

WHITE, Peter. Evaluative semantics and ideological positioning in journalistic discourse. A new framework for analysis. En: I. Lassen, Mediating Ideology in Texts and Images. Amsterdam: John Benjamins Publishing Company, pp. 3769, 2006

Recebido em Março de 2020 Aprovado em Maio de 2020 